\title{
Comparison of multiaxial fatigue parameters using biaxial tests of Waspaloy ${ }^{\text {th }}$
}

\author{
J.V. Sahadi ${ }^{\mathrm{a}, *}$, R.J.H. Paynter ${ }^{\mathrm{a}}$, D. Nowell ${ }^{\mathrm{a}}$, S. J. Pattison ${ }^{\mathrm{b}}$, N. Fox ${ }^{\mathrm{b}}$ \\ ${ }^{a}$ Department of Engineering Science, University of Oxford, Parks Road, Oxford OX1 3PJ, UK \\ ${ }^{b}$ Rolls-Royce plc, PO BOX 31, Derby, Derbyshire, DE24 8BJ, UK.
}

\begin{abstract}
In laboratories most fatigue testing is uniaxial as many aeronautical components such as wing spars are uniaxially loaded. However important components, such as aero engine disks, operate under multiaxial loading conditions. Hence multiaxial data is desirable to safely design them. This paper describes biaxial fatigue tests carried out under a range of loading conditions with cruciform specimens made of Waspaloy, a nickel based superalloy widely used in the fabrication of aero engine disks. Finite Element modelling of the specimen was performed to set the test conditions and to predict stress-strain fields and failure location. In order to investigate the effect of strain biaxiality, different biaxiality ratios with the same maximum principal stress were considered. Results demonstrate a variation in total life to failure and failure location, confirming the FE predictions. Then the experimental results obtained were used with three groups of multiaxial criteria. Initially, von Mises and elastic strain energy density yield theories were extended to the multiaxial fatigue context. Secondly, the stress invariant based criterion proposed by Crossland was considered, where the maximum shear stress amplitude was calculated through the Minimum Circumscribed Circle and the Maximum Prismatic Hull methods. Lastly, the critical plane approach was investigated by considering the propositions made by Findley and Matake. In general all the criteria probed here gave good predictions. As for the first group, better correlation was obtained with the energy parameter. For the last two groups, Crosslands formulation performed the best, with close agreement with experimental observations. The critical plane criteria gave conservative predictions for uniaxial stress cases and non-conservative for the other assessed conditions. In addition, both criteria misbehaved outside their calibration region, i.e. outside the tension-torsion region, and were unable to properly describe equi-biaxial conditions.
\end{abstract}

Keywords: Multiaxial Fatigue, Superalloys, Aircraft Engineering 2016 MSC: 00-01, 99-00

\section{Introduction}

Aircraft failure and repair pose potentially costly and serious problems in the airline industry. The safety of mechanical components is strongly related to the dynamic forces acting during their

\footnotetext{
${ }^{\text {th }}$ Manuscript for Special Issue of International Journal of Fatigue.

${ }^{*}$ Corresponding author

Email address: joao.sahadicavalheiro@eng.ox.ac.uk (J.V. Sahadi)
} 
operation. Component failure due to cyclic loading is characterized by the initiation and subsequent propagation of one or more cracks. The progressive material degradation is fundamentally related to the accumulation of plastic deformation at different length scales.

Even though most fatigue testing is done uniaxially due to its simplicity and inexpensiveness, components and structural parts are rarely subjected to such loading modes during real operation. In practice, a combination of variable loads applied in multiple directions is observed. A particularly important application, in this context, is that of aircraft engine disks, whose main function is to position blades within the airflow and transmit the generated power to a shaft. Under normal working conditions, these disks can reach rotational speeds of 10,000 rpm which combined with metal temperatures of up to $600^{\circ} \mathrm{C}$ results in high centrifugal and hoop stresses, thermal gradients and vibrational loading [1. Thus, the webs, cobs and bore of a disk are all multiaxially loaded.

A common practice in the industry is to combine uniaxial results with conservative safety factors for a safe design of multiaxially loaded components. However, such an assumption is potentially unsafe. First because the correlation between uniaxial and multiaxial results is not well understood and second due to the errors introduced by this simplification. In this regard, as safety and weight/efficiency are major concerns in the aircraft industry, aero engine components are designed using multiaxial criteria and experimental data collected from multiaxial tests. However, the models presented so far still have limitations concerning, for example, the presence of complex loads, non-proportional cyclic hardening and effects of loading trajectory. Therefore, despite a significant body of work in this area, there is no universal consensus on the most efficient criterion for estimating multiaxial fatigue failure. The current paper describes a series of biaxial fatigue experiments in association with multiaxial criteria assessments, aimed at improving our understanding of the behaviour of Waspaloy.

\subsection{Background}

Initially, the multiaxial fatigue problem was addressed using yield theories, where a general equivalent stress could be used to quantify fatigue damage. The most famous yield criteria extended to multiaxial criteria are those proposed by von Mises (distortion energy [2]), Tresca (maximum shear stress [3]) and the strain energy density. These formulations correlate the multiaxial stress state to simple scalar parameters, which can be calibrated under uncomplicated and inexpensive uniaxial tests. The drawback of these straightforward criteria is that they are not suitable for outof-phase or non-proportional conditions as the formulations have a fixed tension-torsion relation [4], [5] and [6].

The first systematic multiaxial fatigue testing work was conduced in the 1930s by Gough and Pollard 7], who designed and built high speed testing machines to investigate the combined effects of bending and torsional stresses (with and without mean stresses) on fatigue life. This set of experiments was used as a benchmark for the early multiaxial fatigue criteria, such as the empirical proposition of Gough [8] (for ductile steels and cast-irons) and the first stress based multiaxial criteria.

Stress based formulations are normally classified into three categories, according to the stress measures used to quantify the fatigue damage associated with a given load history [9], [10]. In the first group, named Stress Equivalent/Stress Invariant approaches, Sines [11, [12] studied the effect mean stresses by analysing the results obtained by Gough and Pollard and concluded that the alternating shear stress should be used as the damage parameter. In this sense, Sines proposed a criterion based on the octahedral shear stress (which takes into account the effect of slippage in material planes) and the hydrostatic stress (which represents the mean normal stress effect). 
Following, Crossland [13] modified Sines criterion by taking into account the mean normal stress effect through the maximum hydrostatic stress.

More recently invariant-based criteria for HCF have been proposed by associating the normal stress measure with new methodologies to calculate the shear stress amplitude. For instance, Gonçalves et al. [14 proposed a criterion that considers the shear stress amplitude calculated with the minimum circumscribing ellipsoid method and the maximum principal stress of the stress history (a contrasting feature as most models in this class consider the hydrostatic stress). Cristofori and Tovo [15] followed the same trend and introduced an stress invariant criterion based on the association of a new formulation for the equivalent amplitude of the deviatoric component and the hydrostatic stress.

Second, a class of methods is based on the search for the critical planes, where a particular stress quantity reaches its maximum magnitude. This methodology have gained great attention over the past 40 years as it mathematically describes the physical phenomenon and is capable of predicting damage and also the crack orientation (for ductile materials cracks typically nucleate along slip planes, where the maximum shear stress occurs [16] and [[4]]). Findley [17] took Gough and Pollard set of experiments into account and proposed the first critical plane based criteria, according to it the maximum damage occurs on a plane where the linear combination of the shear stress amplitude and normal stress is maximum. Matake 18 proposed a similar criteria, however as pointed out by Papadopoulos [19], this formulation contrasts to Findley's as it correctly predicts the torsional and normal mean stress effects. More recently Araújo et al. [10] also contributed to this class of methods.

Finally, Integral approaches form the third class of stress based criteria; in this class an effective shear stress is obtained by averaging the resolved shear stress acting on all cutting planes of a representative volume element. In comparison with the critical plane approach, the integral approach defines fatigue damage as the integral value of the shear stresses acting on all planes rather than the amplitude of the shear stress acting on a single critical plane. Important propositions were made by Socie [20, Fatemi and Kurath 21], Papadopoulos [22] and more recently by Morel and Huyen [23].

This contribution focuses on the first two classes (Stress invariant and Critical Plane based approaches) and extended yield criteria for failure prediction. For a more detailed review on stress based and strain based multiaxial criteria please refer to: [6], [4] and [19]; and for a consistent experimental data base see: 24] and 25].

\subsection{Biaxiality Ratio}

As most fatigue cracks initiate at the free surface, where the maximum direct stress is observed, biaxial tests are required to fully reproduce the plane stress situation. Tension-torsion specimens pose limitations when it comes to probing the entire principal stress plane, $\sigma_{1}$ vs $\sigma_{2}$, and only 2 of its 4 quadrants can be investigated. However with different techniques, such as internally pressurized tubular specimens, it is possible to access more of the principal stress plane. In the current investigation cruciform specimens were used to perform biaxial tests and analyse the biaxiality effect.

Biaxiality of loading can be defined in a number of different ways based on load, stress or strain. We adopt the definition based on strain proposed by Itoh et al. [26], which considers the largest 
magnitude of strain ratio. Mathematically defined in Eq. 1.

$$
\Phi_{\varepsilon}= \begin{cases}\frac{\varepsilon_{2}}{\varepsilon_{1}}, & \text { if }\left|\varepsilon_{2}\right|>\left|\varepsilon_{3}\right| \\ \frac{\varepsilon_{3}}{\varepsilon_{1}}, & \text { if }\left|\varepsilon_{2}\right| \leq\left|\varepsilon_{3}\right|\end{cases}
$$

The intention of our experimental programme is to investigate the effect of strain biaxiality, i.e. to keep one of the maximum principal strains fixed and adjust the other over a range. In Fig. $11 \varepsilon_{x}$ is kept constant and $\varepsilon_{y}$ varies over $\left[-\varepsilon_{x}, \varepsilon_{x}\right] . \varepsilon_{z}$ is simply obtained by strain relationships. This plot has in the abscissa the $\varepsilon_{y} / \varepsilon_{x}$ ratio and in ordinates each of the strain components $\left(\varepsilon_{x}, \varepsilon_{y}\right.$ and $\varepsilon_{z}$ - represented by the dotted and dashed curves) and the biaxiality ratio ( $\Phi_{\varepsilon}$ - represented by the solid black curve). The figure illustrates a wide range of biaxiality ratio, from $\nu$ to $2 \nu$, that cannot be achieved, as there is discontinuity at the point where the in-plane strain exceeds the magnitude of the through strain. Finally, the circles on the solid black curve represents the experimental tests performed.

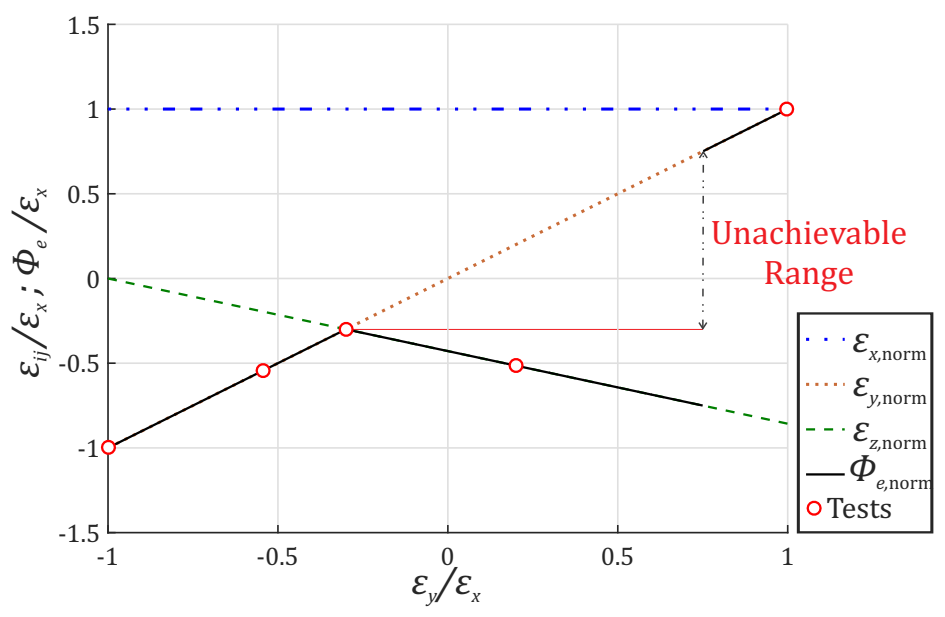

Figure 1: Strains and Biaxiality Ratio as strain ratio $\frac{\varepsilon_{y}}{\varepsilon_{x}}$ varies. $\varepsilon_{x}, \varepsilon_{y}, \varepsilon_{z}$ and $\Phi_{e}$ are all normalized with respect to $\varepsilon_{x}$.

\section{Material}

The specimens tested were cut from an aero engine disk made of Waspaloy ${ }^{\top M}$, a Nickel-based superalloy suitable for high temperature use, although the tests described here were carried out at room temperature. This material presents elevated creep resistance, high fatigue strength, low thermal expansion coefficient and high thermal conductivity, fundamental characteristics to sustain the extreme mechanical and thermal loads which aero engine disks are subject to. As for its mechanical properties, this material has a Young's modulus of 213GPa and a Poisson's ratio of 0.284 .

A metallographic sample was prepared for the determination of grain size. The sample was etched using a solution of Hydrochloric Acid (37\%) and Hydrogen Peroxide $100(>30 \%)$ and then analysed in an Alicona InfiniteFocus microscope (see Fig. 2). Grain measurement was performed according to the Heyn linear intercept procedure as presented in [27] and as a result, an average grain diameter of $43.54 \mu m$ was determined. 


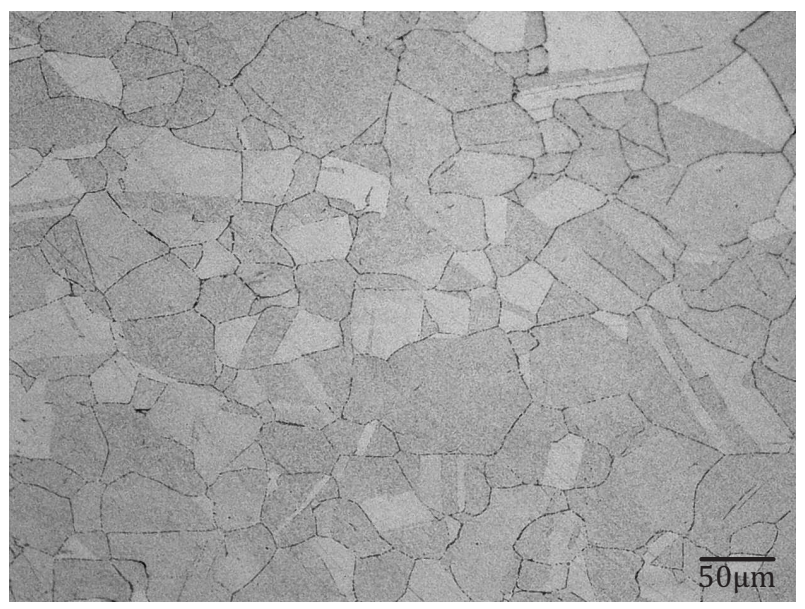

Figure 2: Waspaloy Grain Size

\section{Experimental Methods}

Biaxial fatigue tests were performed using a servo-hydraulic rig, designed and built in the University of Oxford. In total 11 cruciform specimens were used to investigate a wide range of biaxiality ratios, with an initial quasi-static cycle to produce limited plastic deformation, followed by fatigue cycling in the elastic regime until failure. All tests were load controlled and carried out at the same load ratio, $R=F_{\min } / F_{\max }=0.05$, due to physical limitations of the testing machine. This means that in every test there was a mean stress applied to the material, which according to Socie and Marquis [4] and Brown and Miller [16] directly impacts on crack growth. A tensile mean stress reduces fatigue life as it opens the crack tip and facilitates its shearing process.

\subsection{Biaxial Test Rig}

The biaxial rig consists of two independent frames carrying hydraulic actuators such that the perpendicular load vectors meet at the centre of the specimen. The horizontal load path (assumed here as $x$ ) has two actuators working in opposite direction, with capacity of $100 \mathrm{kN}$ each. For the vertical load path $(\mathrm{y})$, the second frame contains a large actuator (350 $\mathrm{kN}$ capacity) at the bottom and a fixed clamp at the top. A set of springs connect both frames and allows vertical movement of the horizontal actuators according to the deformations of the specimen, so that the loads are almost perpendicular at all loads. The complexity of the tests and the size of the actuators and specimen mean that tests can only be carried out at relatively low frequency, $0.5 \mathrm{~Hz}$.

Each actuator has its own dedicated PID controller and these were connected to each other with PC based software to allow fully synchronised loading and potentially complex load sequences, although only proportional in-phase loading was considered. Figure 3 schematically presents the biaxial test rig.

Strain gauges were connected to the measurement system, and each channel balanced before the specimens were clamped into place. Hence, changes in loads occurring during the clamping process could be monitored. In addition, strain gauges on the arms of the specimen were used to monitor bending due to misalignment of the rig. If a moderate tension is applied to the horizontal axis then the difference between top and bottom strain gauges shows whether bending is present.

The tests were terminated based on the presence of visible cracks. In this sense, the tests were carefully set up on tight displacement limits, if tripped the tests would automatically stop and an 


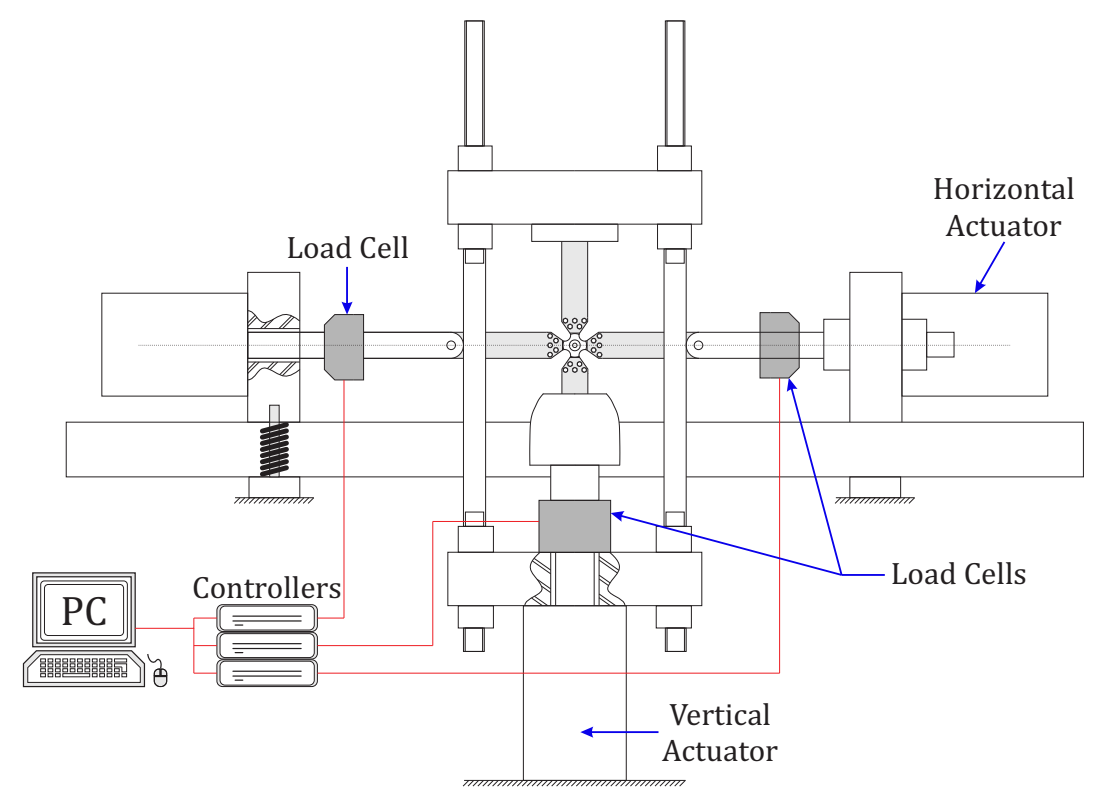

Figure 3: Biaxial test rig developed at the University of Oxford - Schematic diagram.

inspection of the specimen would be performed. If visible cracks were spotted, then the current fatigue life would be recorded and considered as final.

\subsection{Cruciform Specimen}

Cruciform specimens were used with a reduced thickness gauge section at the centre. Its geometry is akin to a Maltese cross, $190 \mathrm{~mm}$ across. The arms are $28 \mathrm{~mm}$ wide at the narrow point, widening to $88 \mathrm{~mm}$ to include five M12 mounting bolt holes and an $8 \mathrm{~mm}$ alignment hole. The arms are $12 \mathrm{~mm}$ thick at the bolting location; the central portion is $7 \mathrm{~mm}$ thick, ultimately enclosing the $2 \mathrm{~mm}$ thick, $15 \mathrm{~mm}$ diameter gauge section. The centre portion (excluding the gauge section) was peened to increase the fatigue strength of the external edges between the arms and hence to discourage failure away from the gauge section. In total 12 strain gauge rosettes were mounted on both front and back face of the gauge section and at the narrow point of the arms. The outputs from these were recorded, together with the applied loads, to determine a calibration of the specimen. A schematic of the specimen and the loads applied is shown in Fig. 4 .

The arms of the specimen were clamped between two plain faced jaws, thus the force is transmitted primarily by friction. To reduce the chance of slip, the faces of the specimen were abraded with coarse silicon carbide paper and cleaned with solvents to remove any grease. The jaws were clamped with five bolts per arm; these were tightened to at least $60 \mathrm{kN}$ per bolt. The highest arm load was $175 \mathrm{kN}$, so that a coefficient of friction of at least 0.3 is needed to prevent slip at the jaws. 


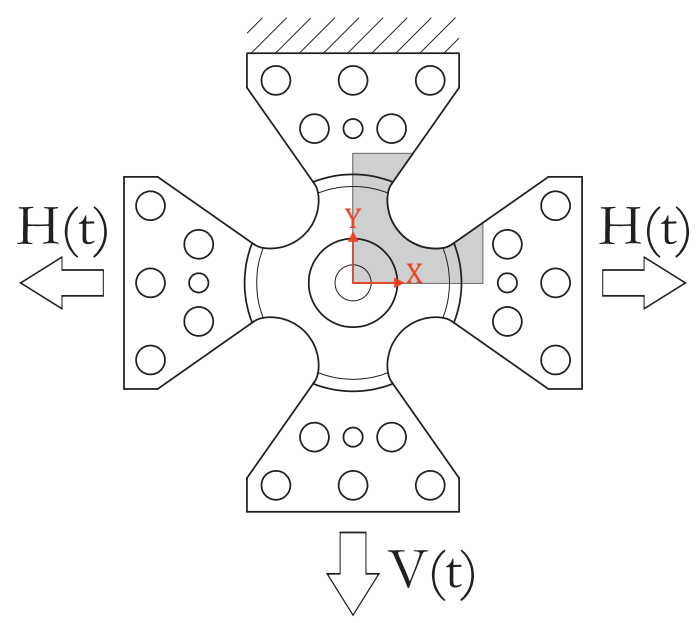

Figure 4: Cruciform specimen and applied loads

\subsection{Load Combinations}

Five different loading cases were establish as to have the same maximum principal stress in each case, and to vary the other in-plane principal stress. As the gauge section is only $2 \mathrm{~mm}$ thick and $15 \mathrm{~mm}$ across, it was assumed that the local behaviour is equivalent to plane stress conditions, i.e. that the stress in the through thickness direction is zero. The following combinations were used:

- Equal biaxial tension (EB) - The specimen is symmetrical so when the loads on the arms are equal; the stress on both axes are also the same.

- Pure shear (PS) - Loads on the two axes are equal and opposite. Hence the vertical actuator applied compressive load and the horizontal tensile load.

- Single Actuator (Uniaxial Load - UL) - Only the vertical actuator applies load. In practice, all actuators were attached but the other axis was controlled to apply zero load.

- Uniaxial Stress (US) - Loads are applied so that the stress seen at the gauge section is equivalent to an uniaxial tensile test.

- Minimum von Mises (Mv): The combination of loads, with $\sigma_{1 \text {,peak }}$ fixed, that gives the minimum von Mises equivalent stress at the gauge section.

\section{Results}

\subsection{Finite Element Method}

Finite element modelling was employed to analyse the specimen and to establish the relationship between load and stress or strain, not obvious for the cruciform specimen. Then, this was used to set the experimental conditions (estimate the loads required for each test), and actual strain gauge readings were used to confirm whether the required value was achieved. Due to the symmetry of the problem only one eighth of the specimen was simulated with appropriate boundary conditions imposed to the symmetry planes. A structured mesh was created with 159,792 linear hexahedral 
elements, 180,700 nodes and reduced Gauss integration points. In order to more accurately describe the stress/strain state a more refined mesh was applied to the region were failure was expected to occur. Thus, the gauge region presents elements of $0.125 \mathrm{~mm}$, amounting to 10,776 elements and 12,454 nodes.

Simulations of each load combination were performed in two steps, first elastic and then elastoplastic analysis, considering the maximum von Mises equivalent stress and the maximum effective plastic strain respectively. The specimen cut used to illustrate the FE results are represented by the grey area in Fig 4 (only the region of interest is displayed, i.e. the clamp region was cropped out). The plastic behaviour was modelled considering a linear hardening law

$$
\sigma_{\text {yield }}\left(\varepsilon_{\mathrm{eff}}^{p}\right)=\sigma_{\text {yield } 0}+H \varepsilon_{\mathrm{eff}}^{p},
$$

where $\sigma_{\text {yield } 0}$ and $\sigma_{\text {yield }}$ represent the initial and current yield stress repesctively, $H$ is the hardening modulus and $\varepsilon_{\mathrm{eff}}^{p}$ is the effective plastic strain. The yield surface is given by:

$$
f\left(\sigma_{i j}\right)=\sigma_{\text {eff }}-\sigma_{\text {yield } 0}\left(\varepsilon_{\text {eff }}^{p}\right)=0,
$$

where $\sigma_{\text {eff }}$ is an effective stress.

Figures $5 \mathrm{a}$ and $5 \mathrm{~b}$ present the elastic and plastic analysis of the biaxial loading case. This highlighted that yielding first occurs at the edge of the specimen, between the arms (Fig 5a). However, as the next step demonstrates in Fig [5b, this was not a practical issue because at full load greater plastic strain occurs within the gauge section, with the maximum effective plastic strain concentrated near the edge. Figures $5 \mathrm{c}$ and $5 \mathrm{~d}$ show that during the elastic step of pure shear the maximum von Mises occurs at the edge of the gauge section, and for the plastic step the maximum plastic strain occurs at the exact centre of the specimen. Lastly the result for the uniaxial equivalent loading case shows that for the elastic step the maximum von Mises also occurs at the edge of the specimen, between the arms (5e), and during the plastic step the maximum plastic strain is located at the edge of the test zone, in the direction of the greater load (5f).

\subsection{Experimental Tests}

Table 1 summarizes the results obtained after testing 11 specimens. In addition, the map of peak stresses in the two principal directions $\left(\begin{array}{llll}\sigma_{1} & \text { vs } & \sigma_{2}\end{array}\right)$ graphically represents the test cases (Figure 6). This gives a diagrammatical summary of the load conditions, with life to failure ('000 cycles) shown below each case point. von Mises and elastic strain energy contours were plotted in Figure 6 as guides to represent the initial elastic domain of Waspaloy.

Initial tests compared different biaxialities at the same $\sigma_{1}$, i.e. same $\sigma_{1 \text {,peak }}$ but different $\sigma_{2 \text {,peak }}$ for each test. Later tests for uniaxial stress and pure shear were run at lower stress. In most cases yielding occurred during the first cycle, but no "reversed yielding" was observed when load was removed. Hence subsequent load cycles at the same load level did not cause additional plastic deformation although the material was loaded close to the elastic limit on each cycle.

The first two specimens (CX01 and CX02) were tested to gain experience with the test and establish the limits of the specimen and rig. Initially the first test was carried out under quasistatic single actuator and equi-biaxial conditions and the second trial specimen was used to check the symmetry of the rig. The specimen was mounted rotated $90^{\circ}$ from its normal orientation and taken through an elastic cycle on each actuator axis, then rotated to its normal orientation and the elastic cycle repeated. It could be concluded that strains are symmetrical on the strain gauges, 


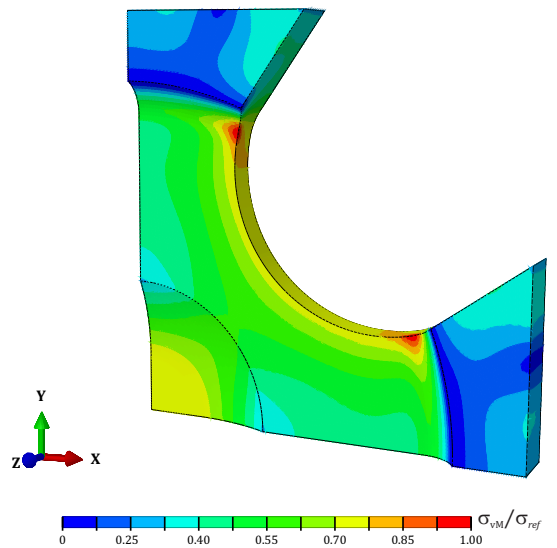

(a)

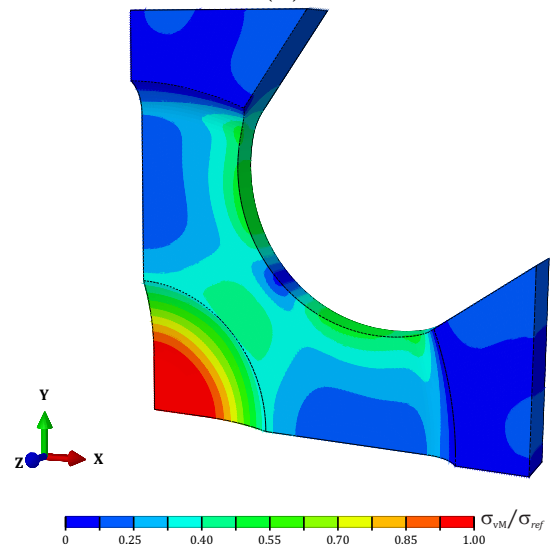

(c)

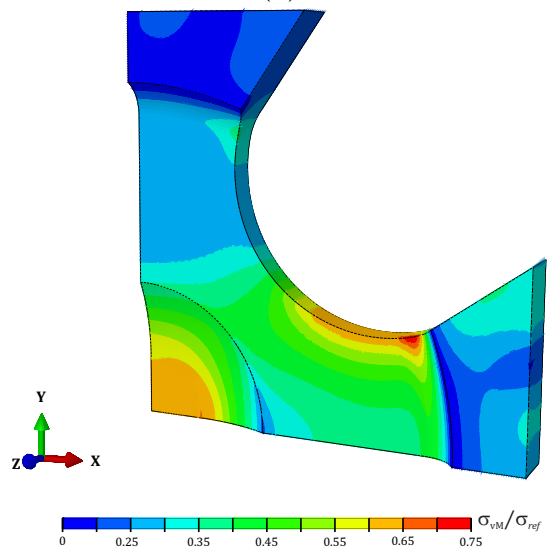

(e)

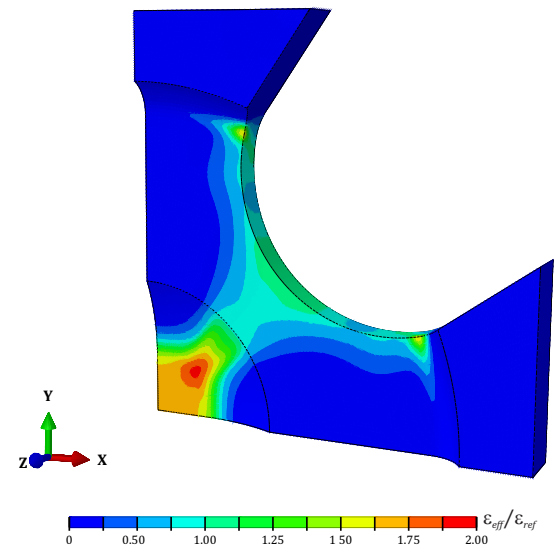

(b)

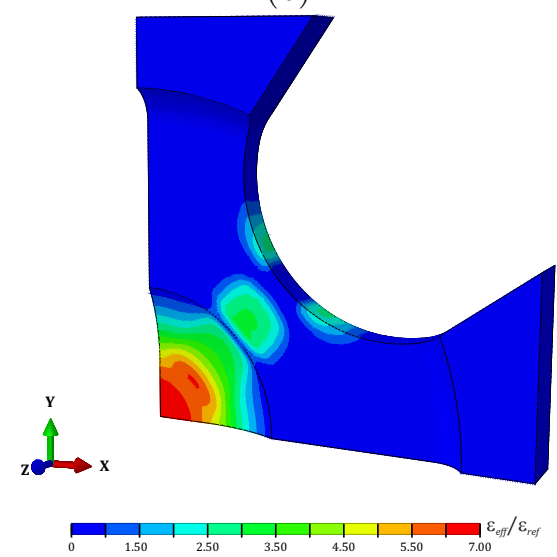

(d)

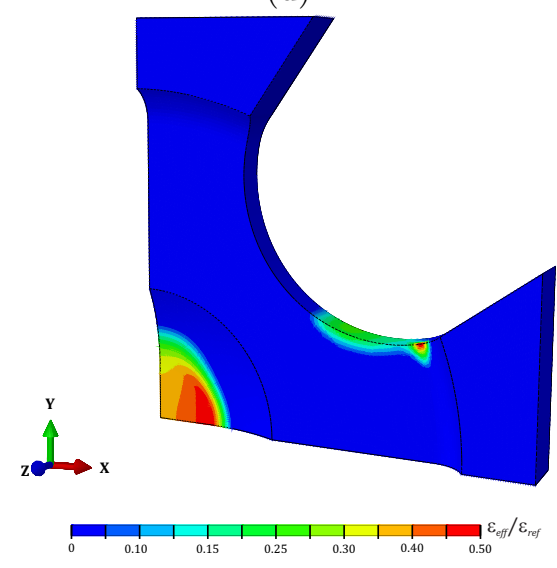

(f)

Figure 5: FE Model. Elastic analysis $\left(\max \sigma_{\mathrm{vM}}\right)$ of: (a) Equi-biaxial, (c) Pure Shear and (e) Uniaxial Equivalent. Plastic Analysis ( $\max \varepsilon_{\text {eff }}$ ) of: (b) Equi-biaxial, (d) Pure Shear and (f) Uniaxial Equivalent. 
and slight mismatches in calibrations of the actuator load cells could be adjusted by reducing the gain for the vertical axis.

The second pure shear test (CX06) was considered a run-out $(510,000$ cycles) as subsequent cyclic loading progressed uneventfully. The uniaxial equivalent test with low stress (CX09) was adjusted to give a maximum principal strain equivalent to the equi-biaxial tests (CX02,CX03) for comparison of results at different levels of biaxiality. The maximum von Mises for this case was below the yield stress of the material and subsequent fatigue loading gave a life of 658,164 (not a run-out).

Strain gauges often failed before the specimen failed. As the crack that causes eventual failure develops, the load transfers to different parts of the specimen and is manifested as a drop in strains for the surviving gauges - both mean and amplitude.

As the most heavily stressed point depends on biaxiality, cracks initiated in different regions depending on the test (always within the gauge section). In both single actuator and uniaxial equivalent tests crack initiated at the edge of the test region and as a final result one arm of the specimen pulled away from the remainder. For equi-biaxial loaded specimens the crack started at the stress concentration near the edge of the thin region and propagated diagonally along a $45^{\circ}$ line, first towards the centre and then across the whole specimen. For pure shear conditions, cracks started at the centre of the gauge section. Therefore, results are coincident with the FE model, and cracks initiate where $\varepsilon_{\text {eff }}$ is maximum (see Fig. 7).

Table 1: Test Parameters.

\begin{tabular}{|c|c|c|c|c|c|c|c|c|c|c|c|c|c|}
\hline \multirow{2}{*}{ Exp. № } & \multirow{2}{*}{ Load Case } & \multicolumn{2}{|c|}{ Peak Load $[\mathrm{kN}]$} & \multicolumn{2}{|c|}{ Norm. Peak Strain } & \multicolumn{3}{|c|}{ Norm. Peak Stress } & \multicolumn{4}{|c|}{ Biaxiality Ratio } & \multirow{2}{*}{ Cycles } \\
\hline & & Horizontal & Vertical & $\varepsilon_{x}$ & $\varepsilon_{y}$ & $\sigma_{x}$ & $\sigma_{y}$ & $\sigma_{\mathrm{vM}}$ & Load & Strain & Stress & $\Phi_{\varepsilon}$ & \\
\hline CX01 & Single Actuator & 117 & 0 & 1.31 & -0.71 & 1.21 & -0.36 & 1.43 & 0.00 & -0.54 & -0.30 & -0.54 & 87,765 \\
\hline CX02 & Equi-biaxial & 170 & 170 & 0.88 & 0.88 & 1.23 & 1.23 & 1.23 & 1.00 & 1.00 & 1.00 & 1.00 & 65,426 \\
\hline CX03 & Equi-biaxial & 170 & 170 & 0.88 & 0.88 & 1.23 & 1.23 & 1.23 & 1.00 & 1.00 & 1.00 & 1.00 & 57,884 \\
\hline CX04 & Single Actuator & 117 & 0 & 1.31 & -0.71 & 1.21 & -0.36 & 1.43 & 0.00 & -0.54 & -0.30 & -0.54 & 97,560 \\
\hline CX05 & Pure Shear & 90 & -90 & 1.56 & -1.56 & 1.21 & -1.21 & 2.10 & -1.00 & -1.00 & -1.00 & -1.00 & 25,789 \\
\hline CX06 & Pure Shear, low $\varepsilon$ & 51 & -51 & 0.88 & -0.88 & 0.69 & -0.69 & 1.19 & -1.00 & -1.00 & -1.00 & -1.00 & 510,000 \\
\hline CX07 & Uniaxial Eq. & 128.5 & 38.5 & 1.21 & -0.34 & 1.21 & 0.00 & 1.21 & 0.30 & -0.28 & 0.00 & -0.28 & 154,396 \\
\hline CX08 & min von Mises & 147.8 & 102.8 & 1.04 & 0.26 & 1.21 & 0.61 & 1.05 & 0.70 & 0.25 & 0.50 & -0.50 & 107,004 \\
\hline CX09 & Uniaxial Eq., low $\varepsilon$ & 93.6 & 28.1 & 0.88 & -0.25 & 0.88 & 0.00 & 0.88 & -1.00 & -0.28 & 0.00 & -0.28 & 658,164 \\
\hline CX10 & Pure Shear, low $\sigma$ & 65.5 & -65.5 & 1.13 & -1.13 & 0.88 & -0.88 & 1.53 & -1.00 & -1.00 & -1.00 & -1.00 & 236,935 \\
\hline CX11 & Pure Shear & 90 & -90 & 1.56 & -1.56 & 1.21 & -1.21 & 2.10 & -1.00 & -1.00 & -1.00 & -1.00 & 21,684 \\
\hline
\end{tabular}




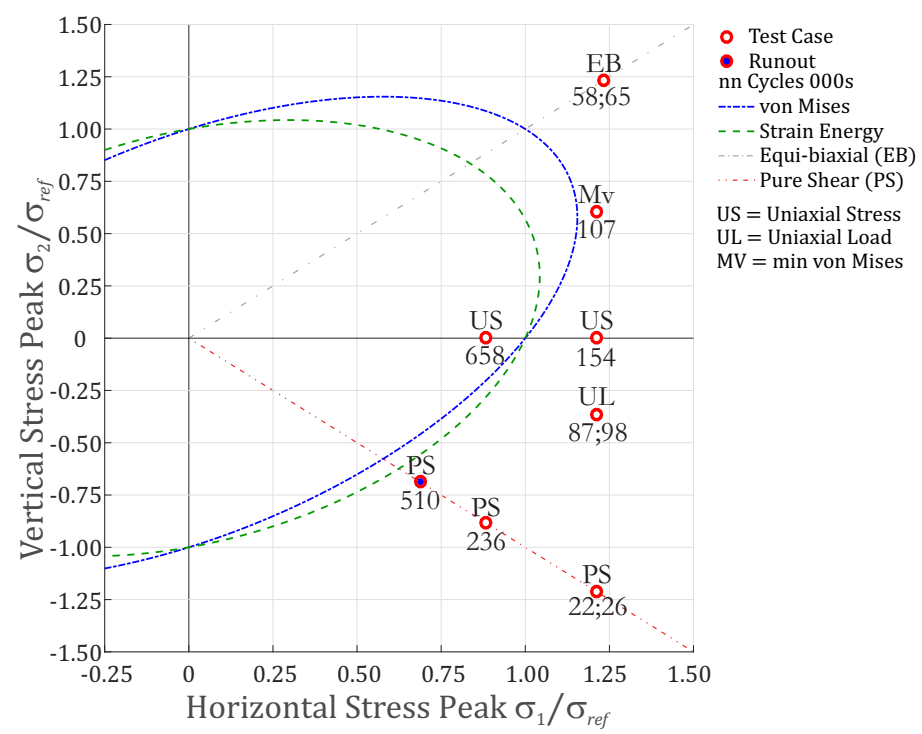

Figure 6: Map of Stress Concentration for $\sigma_{3}=0$. Each point represents a test case. The resulting life is shown in thousands of cycles below each point. For cases with two test results, both values are given.

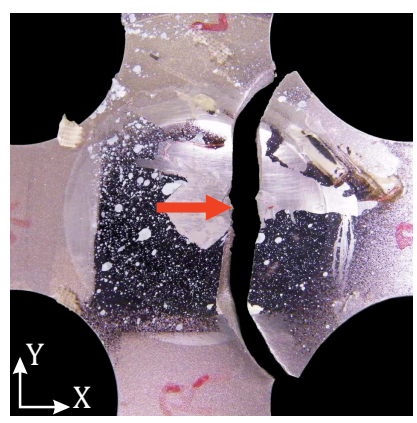

(a)

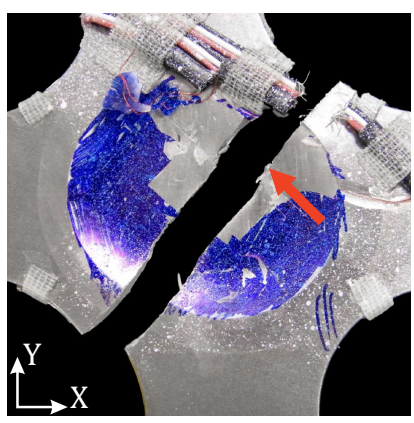

(b)

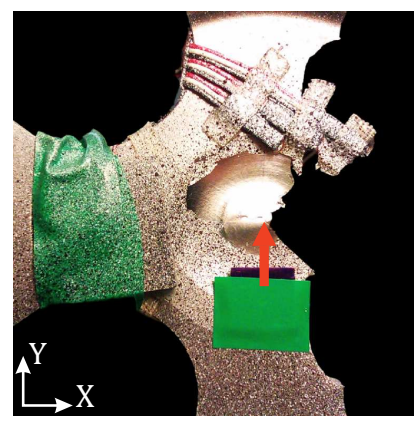

(c)

Figure 7: Failure location for: (a) Uniaxial load, (b) Equi-biaxial Load and (c) Pure Shear.

\subsection{Microscopy}

After the tests some of the broken specimens were analysed using an Alicona InfiniteFocus Microscope and a Carl Zeiss Evo LS15 Scanning Electron Microscope (SEM). the results obtained with the Uniaxial Load (CX04) specimen, Equi-biaxial(CX3) and Pure Shear (CX05) are illustrated in Figs. 8-13. The intention was to analyse the region where the cracks started in three steps. First a microscopy of the gauge section at $5 \mathrm{x}$ magnification was performed with the Alicona, Figs $8 \mathrm{a}$ and 9 a illustrate that for uniaxial load and equi-biaxial failure initiate at the edge of the gauge section, roughly at $45^{\circ}$. For the pure shear case, Fig.10a shows that failure initiated next to the centre of the specimen.

After spotting the crack initiation site, the specimens were analysed at the SEM (Figs $8 \mathrm{~b}, 9 \mathrm{~b}$ and 10b), as the second step of this investigation. Lastly, a profile of the fracture surface for each case specimen was obtained using the Alicona one last time (Figs. 11, 12 and 13). It was concluded after this third step that the crack that had led the uniaxially loaded specimen to failure propagated at $45^{\circ}$ from the initiation location. For the equi-biaxial and pure shear cases the 
propagation occurred at a more shallow angle (almost $0^{\circ}$ ).

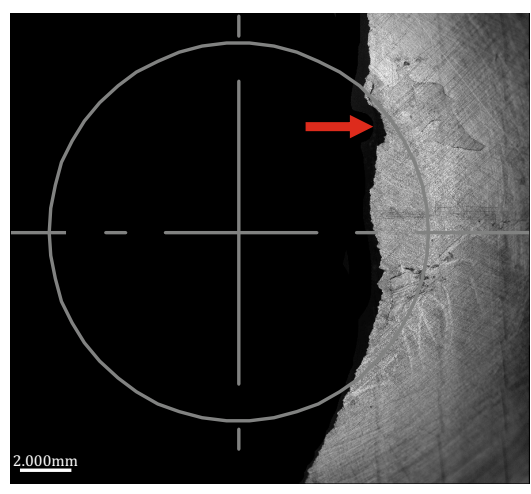

(a)

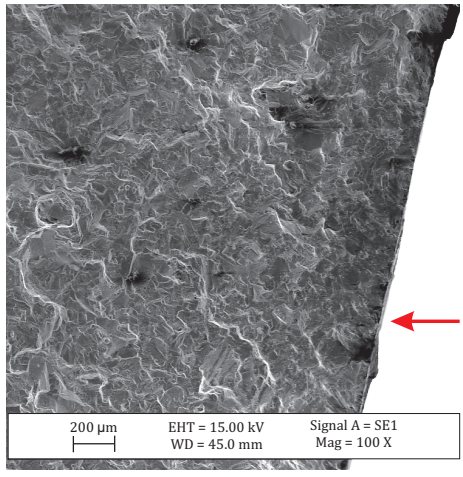

(b)

Figure 8: Failure location for Uniaxial load (single actuator). a) Surface microscopy. b) SEM

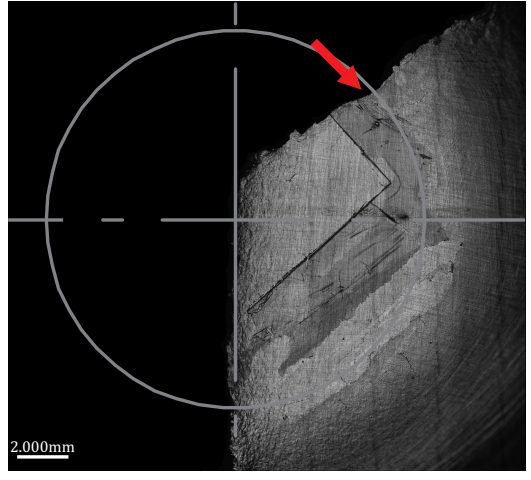

(a)

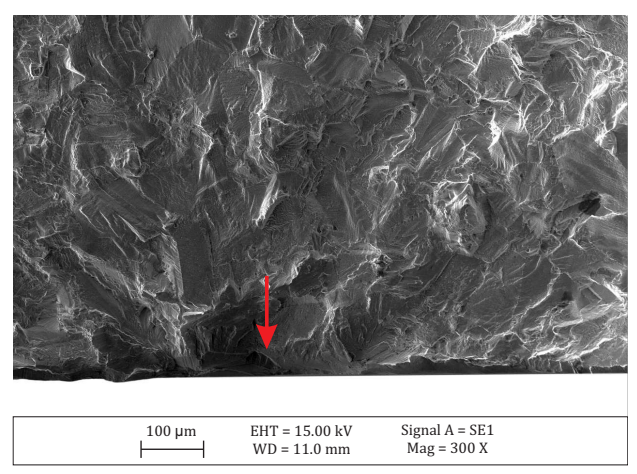

(b)

Figure 9: Failure location for Equi-biaxial. a) Surface microscopy. b) SEM 


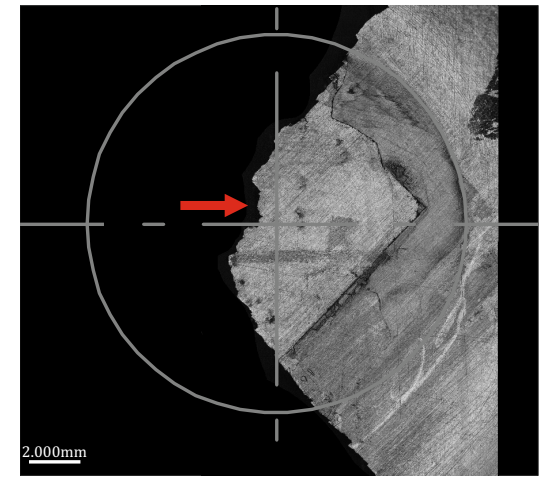

(a)

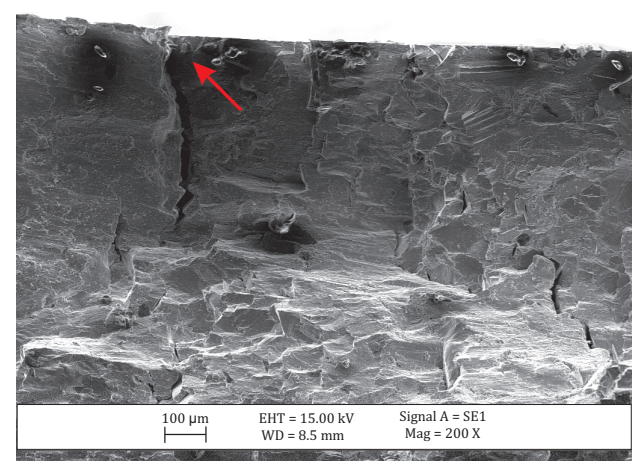

(b)

Figure 10: Failure location for Pure Shear. a) Surface microscopy. b) SEM

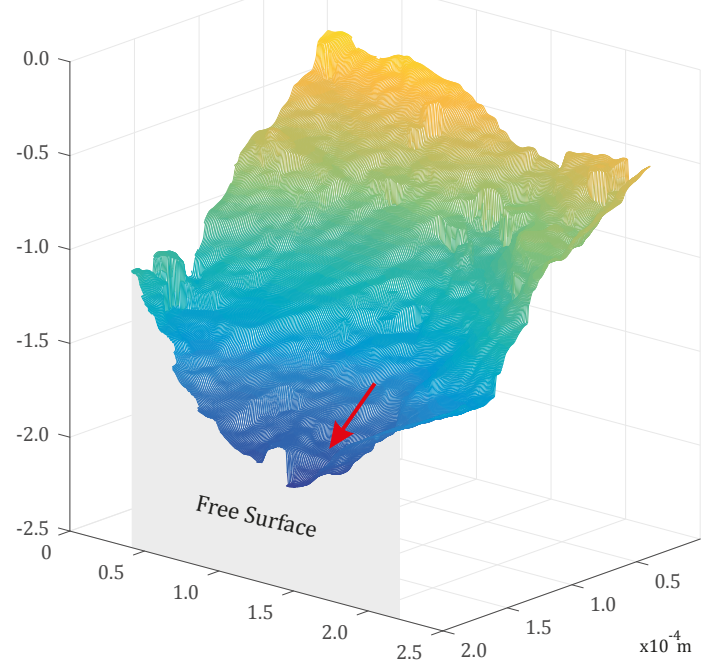

Figure 11: Profile of the fracture surface - Uniaxial load (single actuator). Magnification of 50x

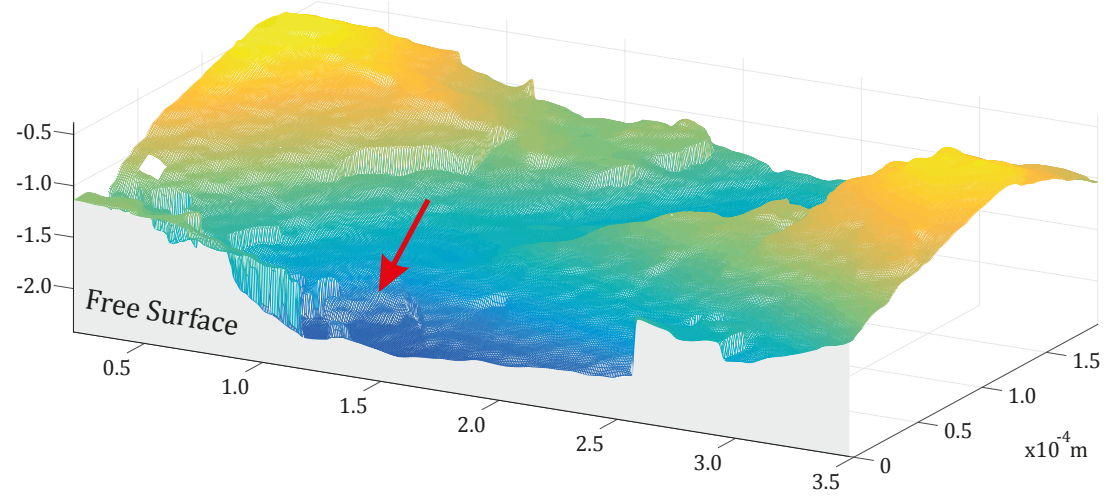

Figure 12: Profile of the fracture surface - Equi-biaxial. Magnification of 50x 


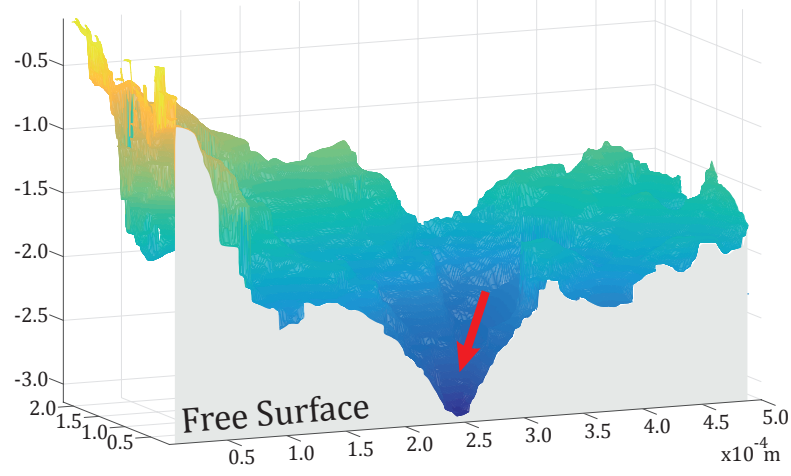

Figure 13: Profile of the fracture surface - Pure Shear. Magnification of 50x

\section{Analysis}

\subsection{Static Yield Parameters}

There are two main reasons why static yield parameters are used as candidates for the description of fatigue behaviour of materials under complex multiaxial stress states. The first one is the advantage of using non-complex and inexpensive uniaxial tests, the second is based on the physical phenomenon. Fatigue damage is a local phenomenon controlled by the plastic deformation on the tip of a crack, therefore yield criteria are capable of providing good fatigue predictions.

Static yield parameters characterize the general multiaxial stress state through a scalar quantity. Thus, in order to correlate the experimental results, a single parameter based on a combination of the loads direction can be used. Two simple candidate parameters were examined initially: von Mises equivalent stress and elastic strain energy density. For plane stress and no shear, von Mises equivalent stress can be expressed as:

$$
\sigma_{\mathrm{vM}}=\sqrt{\sigma_{1}^{2}+\sigma_{1}^{2}-2 \sigma_{1} \sigma_{2}}
$$

where $\sigma_{1}$ and $\sigma_{2}$ represents the principal stress components, in this case equal to $\sigma_{x}$ and $\sigma_{y}$.

Elastic strain energy density is suggested as an appropriate parameter for predicting initiation life. Hence, it was also calculated. The elastic strain energy density is the sum of the products of strain and stress (divided by 2). In the case of plane stress and no shear the resulting formula is very similar to von Mises:

$$
\sigma_{\mathrm{Ue}}=\sqrt{\sigma_{1}^{2}+\sigma_{1}^{2}-2 \nu \sigma_{1} \sigma_{2}}
$$

where $\nu$ represents the Poisson's ratio.

Both parameters were normalized and plotted against cycles to failure in Fig. 14. The stresslife curves were obtained using Basquins relation (power relationship). The general trend for von Mises peak stress is reasonable $\left(r^{2}=0.655\right)$, but shows significant scatter. On the other hand, the elastic strain energy density presents a better correlation with the experimental data $\left(r^{2}=0.868\right)$. Considering the two parameters, the pure shear low stress case was the farthest to the trend line.

\subsection{Stress Based Models - Stress Invariants}

Differently than the initial empirical fatigue models, stress based criteria are generally formulated to take into account the physical effects governing fatigue. In this sense, shear stress 


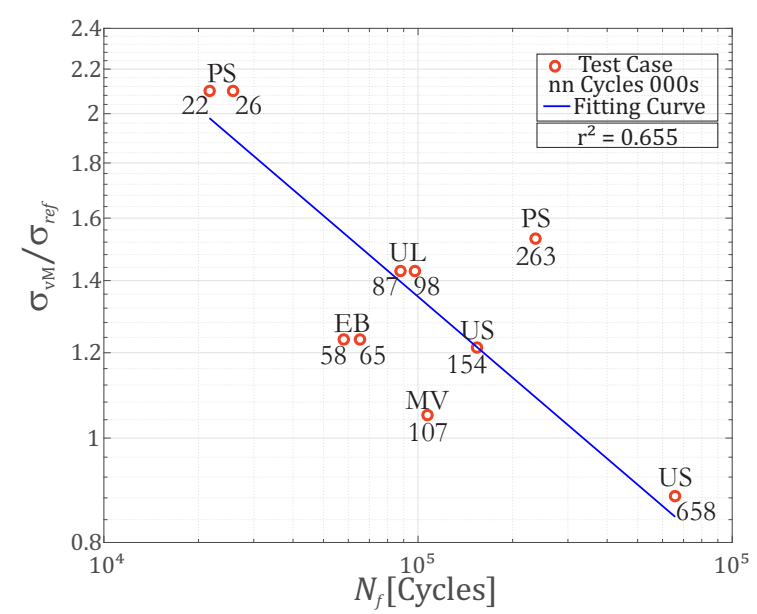

(a)

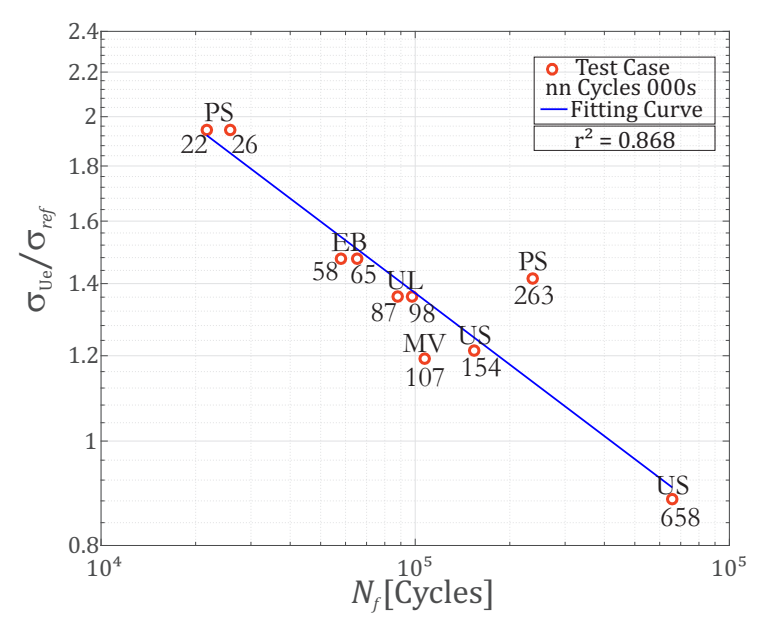

(b)

Figure 14: Static Yield Parameters vs. Cycles to Failure. (a) von Mises equivalent stress; (b) elastic strain energy equivalent stress

parameters are incorporated in order to capture plasticity and slippage on material planes, and normal stress functions introduce the effect of mean stress and nucleation of micro-cracks (opening/closing of them). In general this class of multiaxial fatigue models is formulated as:

$$
f(\tau)+\kappa g(\sigma) \leq \lambda
$$

where $f(\tau)$ and $g(\sigma)$ are shear and normal stress functions respectively. $\kappa$ and $\lambda$ represent material parameters, obtained with two independent tests (generally fully reversed or repeated torsion and tension tests).

As these models are typically calibrated under tension-torsion conditions, they tend to give less good predictions outside the calibration region. Figure 15 represents how the results of this formulations are normally presented, in a shear stress amplitude vs measure of normal stress plot. The light grey shade area corresponds to the calibration region (tension-torsion)". and is delimited by the uniaxial tension and uniaxial compression dashed lines. The darker grey shade area delimited by the equi-biaxial line is of particular interest for this work, as many test cases lie in this region. Different line fonts exemplify fatigue life thresholds, i.e. a test case below a line is predict to have a longer life than the threshold of the line. On the other hand, a point above it represents a test case with shorter life.

In this contribution, the fatigue strength of Waspaloy for fully reversed $(R=-1)$ and repeated $(R=0)$ tensile tests were provided by Rolls-Royce plc. However, the torsional fatigue data for the calibration of the models were not available to the authors. Therefore, they were estimated based on the pure shear tests performed with the cruciform specimen and on a relationship stablished between torsional and uniaxial fatigue strength. It was observed that for Waspaloy this correlation is not constant. In fact the torsional fatigue strength ranges between 0.55 and 0.80 of the uniaxial fatigue strength. For this reason, the fatigue thresholds presented in the result images (Figs. $17-$ 19.) are not parallel to each other. Despite that, the results obtained with this relationship present 
a good correlation with the experimental data.

$$
\tau_{-1}= \begin{cases}0.55 \sigma_{-1}, & \text { For } N_{f}=10^{4} \text { cycles } \\ 0.70 \sigma_{-1}, & \text { For } N_{f}=10^{5} \text { cycles } \\ 0.80 \sigma_{-1}, & \text { For } N_{f}=10^{6} \text { cycles }\end{cases}
$$

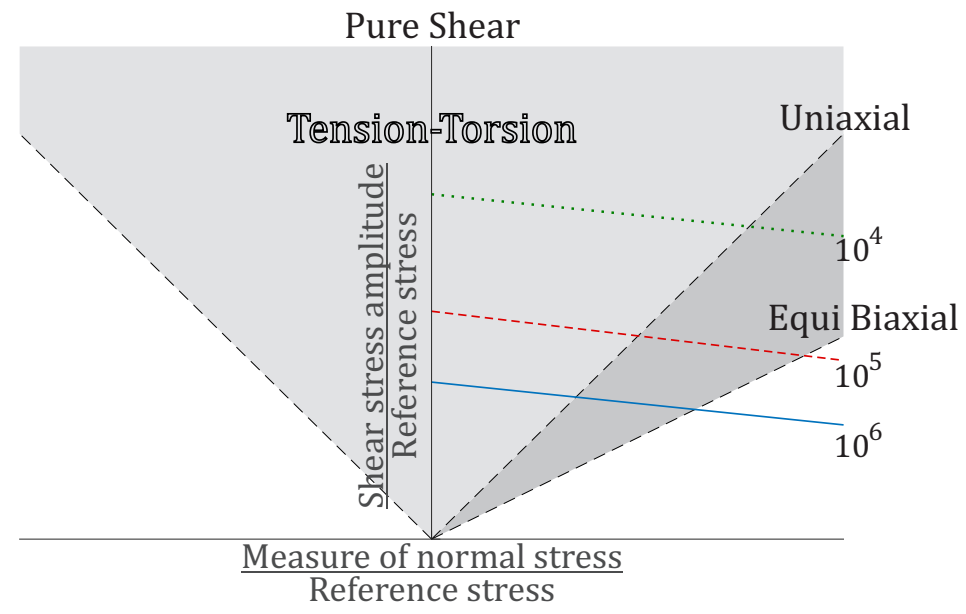

Figure 15: Typical result representation of stress based multiaxial fatigue models

Following the stress based criterion proposed by Crossland [13] was taken into account. Originally this model was formulated considering the amplitude of the second invariant of the deviatoric stress tensor, $J_{2 a}$ (which corresponds to the amplitude of von Mises equivalent stress), and the maximum value of the first invariant of Cauchy's stress tensor, i.e. the maximum hydrostatic stress $\left(\sigma_{h, \max }\right)$. In this contribution this model was formulated as follows:

$$
\frac{\tau_{a}}{\sqrt{2}}+\kappa \sigma_{h, \max }=\lambda
$$

with its material constants, $\lambda$ and $\kappa$, summarized in Tab. 2. $\tau_{a}$ represents the shear stress amplitude, calculated here using two different methods. In the first, the shear stress amplitude is considered as the radius of the smallest circle that involves every point of the loading history, Minimum Circumscribed Circle (MCC) 28. In the second, the maximum rectangular Prismatic Hull (PH) enclosing the stress history projected onto deviatoric stress space is used to define the shear stress amplitude 9]. Figure 16 illustrates both methods. For the current case, proportional loading and $\mathrm{R}=0.05$, both methods calculate the same shear stress amplitude. However, the $\mathrm{PH}$ is more efficient computationally.

Figure 17 presents the results obtained using Crossland's formulation. As the result with both methods (MMC and $\mathrm{PH}$ ) was the same, only one figure is needed to represent it. The dashed lines connect test cases with the same $\sigma_{1 \text {,peak }}$, in order to illustrate the biaxiality effect when $\sigma_{2 \text {,peak }}$ is changed. In practice, this formulation presented good correlation with the experimental data, where non conservative predictions were observed for negative values of $\sigma_{2 \text {,peak }}$ (pure shear and uniaxial load cases - CX01, CX04, CX05 and CX10). On the other hand, as $\sigma_{2, \text { peak increases }}$ towards higher positive values the criterion becomes proportionally more conservative (min von 


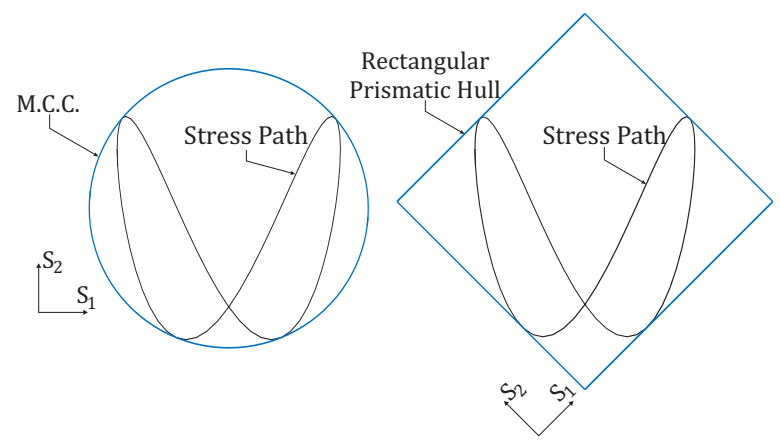

Figure 16: Shear stress amplitude measures: Maximum Circumscribed Circle (MCC) and Prismatic Hull (PH)

Mises and equi-biaxial CX08, CX02 and CX03). Nevertheless this model presented good agreement with the test data both within and outside the calibration region (tension-torsion region), which can be related to the quality of the fatigue strength data.

Table 2: Material parameters for multiaxial criteria.

\begin{tabular}{lcc}
\hline Criterion & $\lambda$ & $\kappa$ \\
\hline Crossland [13] & $\tau_{-1}$ & $3 \frac{\tau_{-1}}{\sigma_{-1}}-\sqrt{3}$ \\
Findley [17] & $\frac{1-0.5 r}{\sqrt{r-1}}$ & $3 \frac{\tau_{-1}}{\sigma_{-1}}-\sqrt{3}$ \\
Matake [18] & $\tau_{-1}$ & $2 \frac{\tau_{-1}}{\sigma_{-1}}-1$ \\
\hline
\end{tabular}

where $r=\frac{\tau_{-1}}{\sigma_{-1}}$ and $\sigma_{-1}$ and $\tau_{-1}$ are the fatigue strength obtained with smooth specimens under fully reversed bending and torsion respectively.

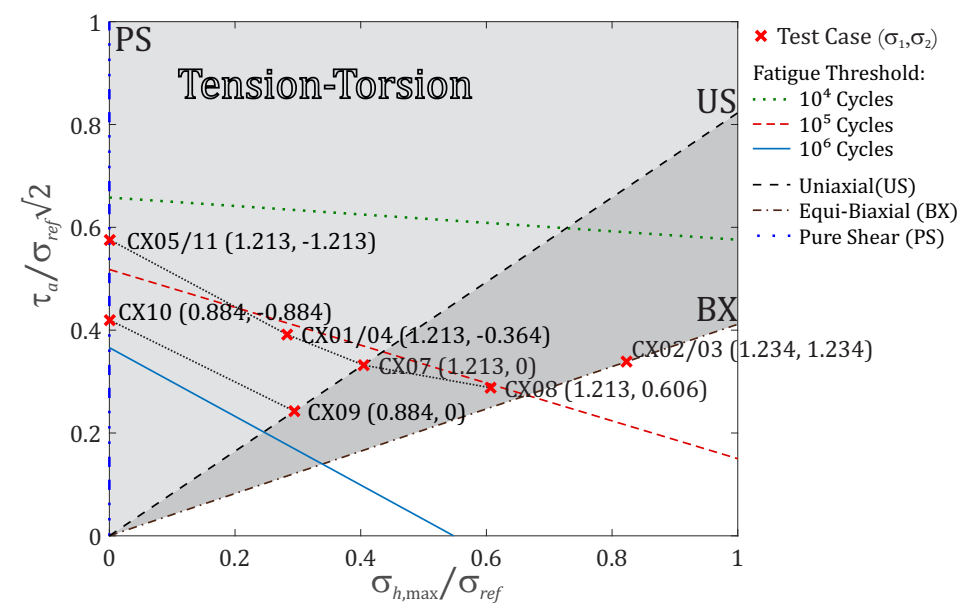

Figure 17: Crossland's multiaxial fatigue model in association with the MCC and with the PH (Same result). 


\subsection{Stress Based Models - Critical Plane Approach}

Findley [17] proposed one of the first multiaxial fatigue criterion based on the critical plane approach, i.e. on the search of specific planes (one or more) where a certain damage parameter is maximum. According to this formulation, failure occurs on the planes where the sum of shear stress amplitude (parameter governing crack progression) and a constant, $\kappa$, times the maximum normal stress (parameter controlling the crack tip opening/closing) is maximum.

$$
\max \left(\tau_{a}+\kappa \sigma_{n, \max }\right)_{\theta, \phi}=\lambda
$$

where $\tau_{a}$ is the shear stress amplitude and $\sigma_{n \text {,max }}$ is the maximum normal stress. $\kappa$ and $\lambda$ are obtained under fully reversed tension and fully reversed torsion respectively. Please refer to Tab. 2 for their values.

Also based on the critical plane concept, Matake [18] proposed a similar criterion where failure occurs on the planes of maximum shear stress amplitude that presents the maximum normal stress. This is mathematically formulated as:

$$
\tau_{a, \max }+\kappa \sigma_{n, \max }=\lambda
$$

where $\tau_{a, \max }$ and $\sigma_{n, \max }$ are the maximum shear stress amplitude and the maximum normal stress respectively. Once again the material parameters, $\kappa$ and $\lambda$, are calculated as given in Tab. 2 , Figures 18 and 19 show the predictions obtained with Findley's and Matake's models correspondingly. In contrast to Crossland's plot, here the uniaxial and equi-biaxial dotted lines are coincident. Papadopoulos et al. 19] concluded after a comparative study that Matake's formulation behaved correctly under mean torsion loads, an improvement when compared with Findley's criterion. The same conclusion can be drawn from the figures, Findley's proposition was unable to correctly evaluate the pure shear cases and only Matake's formulation identified the pure shear cases. In addition, Matake's proposition gave its most conservative prediction for the uniaxial stress condition. Less conservative predictions were obtained for positive values of $\sigma_{2}$,peak, whilst negative values of $\sigma_{2 \text {,peak }}$ (pure shear case) presented its most optimistic results. Similar results were obtained with Findleys model, but generally slightly more conservative.

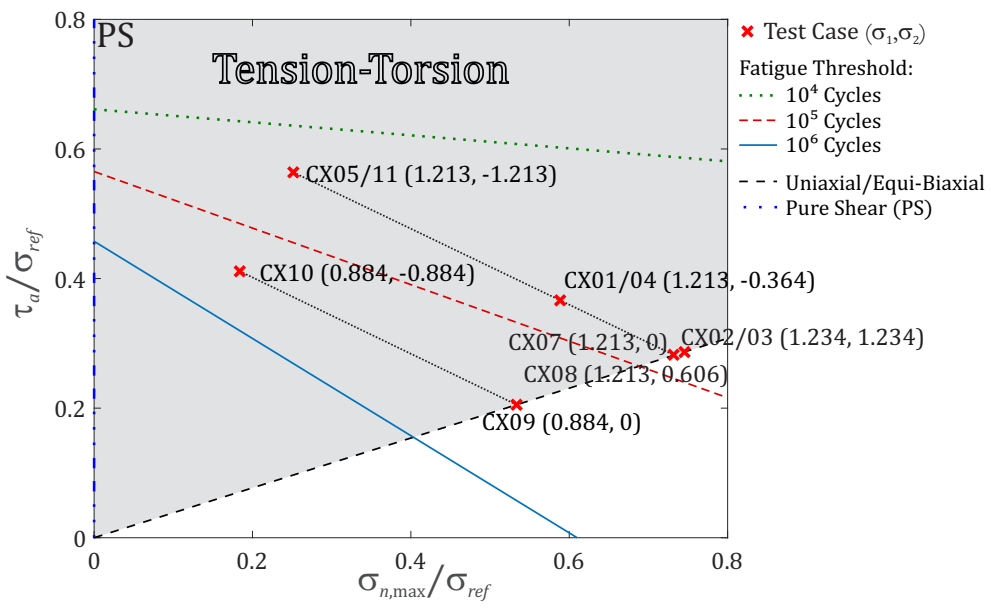

Figure 18: Findley's multiaxial fatigue model. 


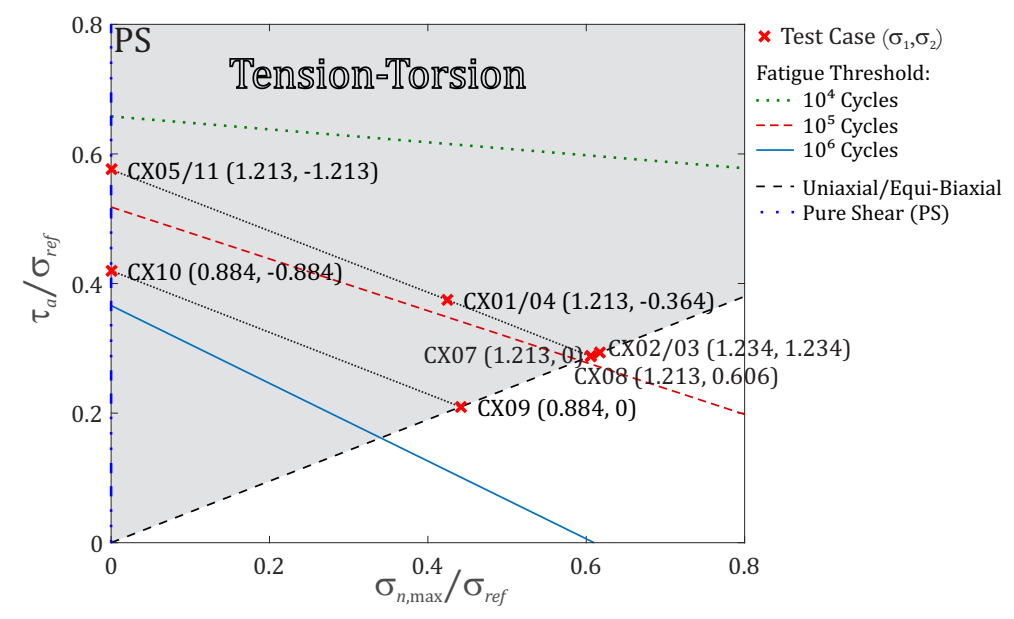

Figure 19: Matake's multiaxial fatigue model.

Finally Fig. 20 graphically summarizes the behaviour observed in practice and expected for fatigue criteria, where life decreases with the increase of $\sigma_{2 \text {,peak }}$ magnitude, i.e. life decreases towards pure shear and equi-biaxial conditions. However, the results demonstrate that no model examined here could capture this reduction in life towards negative values of $\sigma_{2 \text {,peak }}$. In addition, only Crossland's criterion predicted a clear reduction in life towards equi-biaxial cases, confirming the experimental observations.

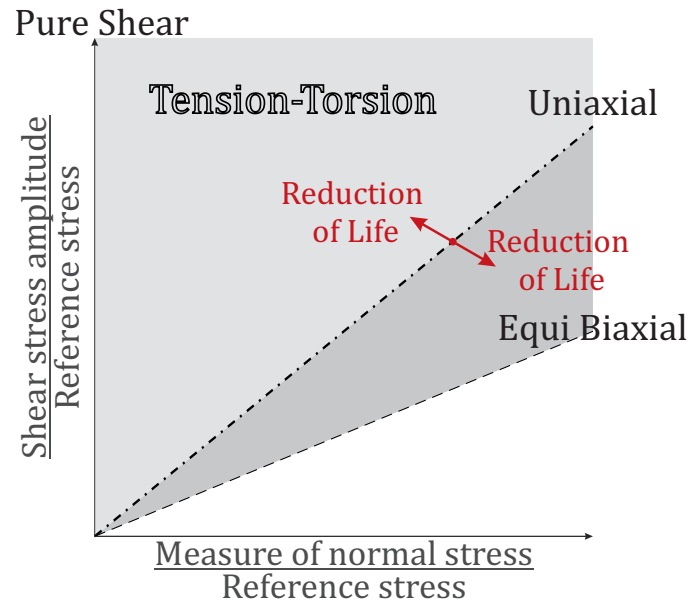

Figure 20: Fatigue behaviour observed in practice and expected for multiaxial fatigue criteria.

\section{Conclusion}

Biaxial fatigue characteristics of Waspaloy were investigated over a range of conditions. With the aid of Finite Element analysis it was possible to set each test for the desired loading conditions, the results obtained with the microscopy investigation confirmed the success of this. As failure occurred where the FE model predicted the maximum effective plastic strain. Fatigue life correlations were obtained considering two measures of the combined peak loads: von Mises equivalent 
stress and elastic strain energy density. The latter parameter presented better agreement with the experimental results, however more sophisticated parameters are needed for non-zero R-ratio and/or non-proportional loading. For such conditions energy based approaches may be used 29 [30].

In addition, predictions of failure were obtained considering two groups of stress based multiaxial criteria. In the first group the model proposed by Crossland was assesed considering the MCC and the PH methods for computing the shear stress amplitude. The results with both methods were exactly the same, however the $\mathrm{PH}$ demonstrated to be computationally more efficient. Further, this methodology is also suitable for non-proportional loading. Regarding the precision of predictions, Crossland's model presented non-conservative behaviour for negative values of $\sigma_{2}$,peak . In contrast, it was the only proposition assessed here to properly describe the reduction in life experimentally observed towards equi-biaxial cases.

Lastly, the second group consisted of stress based critical plane criteria. The models of Findley and Matake were investigated and non-conservative predictions were obtained for non-zero values of $\sigma_{2 \text {,peak }}$. Interestingly Findley's formulation is unable to identify the pure-shear conditions, which Matake's formulation correctly addresses. Even though the latter model is able to identify pureshear conditions, it incorrectly predicts longer lives than the experimental data for pure shear conditions.

It is concluded that the elastic strain energy and Crossland's criteria gave good predictions and that the critical plane models assessed present great limitation for predictions outside their calibration region (tension-torsion region). In addition, the concept of additive parameters does not represent the physical behaviour of materials. In this sense, the use of multiplicative criteria (such as Smith-Watson-Topper [29] and Fatemi-Socie [21]) is of great interest.

\section{Acknowledgements}

The authors are grateful for the support of Rolls-Royce plc and the Brazilian National Council of Technological and Scientific Development (CNPq), grant № 207297/2015-0. A portion of this work was part of a Collaborative R\&T Project SILOET supported by the Technology Strategy Board.

\section{References}

[1] G. F. Harrison, M. B. Henderson, Lifing strategies for high temperature fracture critical components, in: R. D. Townsend, M. Winstone, M. Henderson, J. Nicholls, A. Partridge, B. Nath, M. Wood, R. Vismanathan (Eds.), Proceedings of the Conference on Life Assessment of Hot Section Gas Turbine Components, IOM Communications, 2000, pp. 11-33.

[2] R. Von Mises, Göttinger nachrichten, Math-Phys Klasse (1913) 582.

[3] H. Tresca, Memoire sur lecoulement des corps solides., Mm. pres. par div. sav. 18 (1868) 733-799.

[4] D. Socie, G. Marquis, Multiaxial fatigue, Warrendale, PA: Society of Automotive Engineers, 1999. 502.

[5] J. Bannantine, Fundamentals of metal fatigue analysis, Prentice Hall, 1990, (1990) 273.

[6] A. Fatemi, N. Shamsaei, Multiaxial fatigue: An overview and some approximation models for life estimation, International Journal of Fatigue 33 (8) (2011) 948-958.

[7] H. Gough, H. Pollard, The strength of metals under combined alternating stresses, Proceedings of the institution of mechanical engineers 131 (1) (1935) 3-103.

[8] H. Gough, Engineering steels under combined cyclic and static stresses, Proceedings of the Institution of Mechanical Engineers 160 (1) (1949) 417-440.

[9] E. Mamiya, J. Araújo, F. Castro, Prismatic hull: a new measure of shear stress amplitude in multiaxial high cycle fatigue, International Journal of Fatigue 31 (7) (2009) 1144-1153. 
[10] J. Araújo, A. Dantas, F. Castro, E. Mamiya, J. Ferreira, On the characterization of the critical plane with a simple and fast alternative measure of the shear stress amplitude in multiaxial fatigue, International Journal of Fatigue 33 (8) (2011) 1092-1100.

[11] G. Sines, Failure of materials under combined repeated stresses with superimposed static stresses, Tech. Note 3495.

[12] G. Sines, J. L. Waisman, Behavior of metals under complex static and alternating stresses, Metal Fatigue (1959) $145-169$.

[13] B. Crossland, Effect of large hydrostatic pressures on the torsional fatigue strength of an alloy steel, in: Proc. Int. Conf. on Fatigue of Metals, Vol. 138, Institution of Mechanical Engineers London, 1956.

[14] C. A. Gonçalves, J. A. Araújo, E. N. Mamiya, Multiaxial fatigue: a stress based criterion for hard metals, International Journal of Fatigue 27 (2) (2005) 177-187.

[15] A. Cristofori, R. Tovo, An invariant-based approach for high-cycle fatigue calculation, Fatigue \& Fracture of Engineering Materials \& Structures 32 (4) (2009) 310-324.

[16] M. Brown, K. Miller, A theory for fatigue failure under multiaxial stress-strain conditions, Proceedings of the Institution of Mechanical Engineers 187 (1) (1973) 745-755.

[17] W. N. Findley, A theory for the effect of mean stress on fatigue of metals under combined torsion and axial load or bending, no. 6, Engineering Materials Research Laboratory, Division of Engineering, Brown University, 1958.

[18] T. Matake, An explanation on fatigue limit under combined stress, Bulletin of JSME 20 (141) (1977) $257-263$.

[19] I. V. Papadopoulos, P. Davoli, C. Gorla, M. Filippini, A. Bernasconi, A comparative study of multiaxial highcycle fatigue criteria for metals, International Journal of Fatigue 19 (3) (1997) 219-235.

[20] D. Socie, Multiaxial fatigue damage models, Journal of Engineering Materials and Technology 109 (4) (1987) 293-298.

[21] A. Fatemi, P. Kurath, Multiaxial fatigue life predictions under the influence of mean-stresses, Journal of Engineering Materials and Technology 110 (4) (1988) 380-388.

[22] I. Papadopoulos, A high-cycle fatigue criterion applied in biaxial and triaxial out-of-phase stress conditions, Fatigue \& Fracture of Engineering Materials \& Structures 18 (1) (1995) 79-91.

[23] F. Morel, N. Huyen, Plasticity and damage heterogeneity in fatigue, Theoretical and Applied Fracture Mechanics 49 (1) (2008) 98-127.

[24] B. Weber, A. Carmet, J. Clément, J. Robert, Les criteres de fatigue multiaxiaux et leur application au dimensionnement en fatigue des structures, in: Société Française de Métallurgie et de Matériaux. Journées de printemps, 1999, pp. 29-1.

[25] J. Papuga, A survey on evaluating the fatigue limit under multiaxial loading, International Journal of Fatigue 33 (2) (2011) 153-165.

[26] T. Itoh, M. Sakane, M. Ohnami, High temperature multiaxial low cycle fatigue of cruciform specimen, Journal of engineering materials and technology 116 (1) (1994) 90-98.

[27] A. Standard, E112-13, Standard Test Methods for Determining Average Grain Size. ASTM International, West Conshohocken, PA.

[28] I. V. Papadopoulos, Critical plane approaches in high-cycle fatigue: on the definition of the amplitude and mean value of the shear stress acting on the critical plane, Fatigue \& Fracture of Engineering Materials \& Structures 21 (3) (1998) 269-285.

[29] K. Smith, T. Topper, P. Watson, A stress-strain function for the fatigue of metals(stress-strain function for metal fatigue including mean stress effect), Journal of materials 5 (1970) 767-778.

[30] F. Ellyin, Z. Xia, A general fatigue theory and its application to out-of-phase cyclic loading, Journal of engineering materials and technology 115 (4) (1993) 411-416. 